\title{
Tuning the Photophysical Behavior of Luminescent Cyclam Derivatives by Cation Binding and Excited State Redox Potential
}

\author{
Evan G. Moore, ${ }^{*, \dagger,+}$ Paul V. Bernhardt,${ }^{\dagger}$ Alexandre Fürstenberg,,$^{\S}$ Mark J. Riley, ${ }^{\dagger}$ \\ Trevor A. Smith," and Eric Vauthey ${ }^{\S}$ \\ Department of Chemistry, School of Molecular and Microbial Sciences, University of Queensland, \\ Brisbane, 4072, Australia, Photophysics Laboratory, School of Chemistry, University of Melbourne, \\ Parkville, 3010, Australia, and Physical Chemistry Department, Sciences II, University of Geneva, 30, \\ Quai Ernest-Ansermet, 1211 Geneva 4, Switzerland
}

Received: December 20, 2004; In Final Form: March 9, 2005

\begin{abstract}
The emission from two photoactive 14-membered macrocyclic ligands, 6-((naphthalen-1-ylmethyl)-amino)trans-6,13-dimethyl-13-amino-1,4,8,11-tetraaza-cyclotetradecane $\left(\mathrm{L}^{1}\right)$ and 6-((anthracen-9-ylmethyl)-amino)trans-6,13-dimethyl-13-amino-1,4,8,11-tetraaza-cyclotetradecane $\left(\mathrm{L}^{2}\right)$ is strongly quenched by a photoinduced electron transfer (PET) mechanism involving amine lone pairs as electron donors. Time-correlated single photon counting (TCSPC), multiplex transient grating (TG), and fluorescence upconversion (FU) measurements were performed to characterize this quenching mechanism. Upon complexation with the redox inactive metal ion, $\mathrm{Zn}(\mathrm{II})$, the emission of the ligands is dramatically altered, with a significant increase in the fluorescence quantum yields due to coordination-induced deactivation of the macrocyclic amine lone pair electron donors. For $\left[\mathrm{ZnL}^{2}\right]^{2+}$, the substituted exocyclic amine nitrogen, which is not coordinated to the metal ion, does not quench the fluorescence due to an inductive effect of the proximal divalent metal ion that raises the ionization potential. However, for $\left[\mathrm{ZnL}^{1}\right]^{2+}$, the naphthalene chromophore is a sufficiently strong excited-state oxidant for PET quenching to occur.
\end{abstract}

\section{Introduction}

It has been well-established ${ }^{1}$ that the fluorescence of compounds such as 1-naphthylmethyl- and 9-anthrylmethylamine is strongly $\mathrm{pH}$ dependent, an effect that has been attributed to reductive quenching of the fluorophore by a photoinduced electron transfer (PET) mechanism, where the proximal nitrogen lone pair is the electron donor under alkaline conditions. Upon protonation of the amine, a dramatic increase in the fluorescence intensity results as PET quenching is deactivated. In addition to studies related to its $\mathrm{pH}$ response, ${ }^{2}$ 1-naphthylmethylamine has been recently utilized as a fluorescent $\mathrm{CO}_{2}$ sensor via the formation of a nonfluorescent carbamate, ${ }^{3}$ while 9 -anthrylmethylamine was earlier shown to act as a DNA intercalator, implicating its use as a potential photoactivated sequence specific cleavage reagent. ${ }^{4}$

The incorporation of the naphthalene and anthracene chromophores into photoactive systems based on acyclic polyaza chains and their macrocyclic analogues has also been achieved by several groups, ${ }^{5-7}$ representing a logical step in the evolution of fluorescent molecular sensors based on this design. The presence of additional amine donors can imbue compounds such as these with multistep fluorescent $\mathrm{pH}$ response curves and also establish binding sites specific for other substrates such as $\mathrm{Zn}(\mathrm{II})$, a redox inactive and spectroscopically silent metal ion,

\footnotetext{
* Corresponding author. E-mail: E.Moore@uq.edu.au.

University of Queensland.

$\doteqdot$ Current address: Centre for Biophotonics and Laser Science, Department of Physics, University of Queensland, St. Lucia, Queensland, 4072, Australia.

$\S$ University of Geneva.

"University of Melbourne.
}

CHART 1: Ligands Relevant to This Study
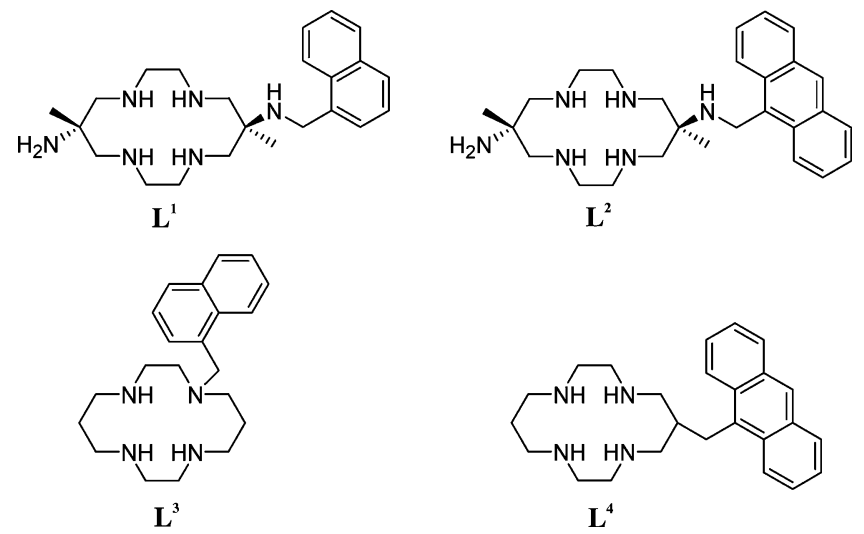

which often enhances ligand fluorescence upon complexation. $6,8,9$

By contrast, redox active transition metals such as $\mathrm{Cu}(\mathrm{II})$, $\mathrm{Ni}(\mathrm{II})$, and $\mathrm{Co}(\mathrm{III})$ can quench the fluorescence of a nearby aromatic fluorophore by both a PET mechanism involving a change in the redox state of the metal or an electronic energy transfer (EET) mechanism with the metals' $d-d$ absorption manifold acting as an energy acceptor. The cyclam macrocycles shown in Chart $1\left(\mathrm{~L}^{3}\right.$ and $\left.\mathrm{L}^{4}\right)$ bearing a covalently appended fluorophore are particularly good examples of this effect. For $\mathrm{L}^{4}$, the characteristic anthracene emission is observed in the free ligand, whereas the addition of $\mathrm{Co}$ (III) results in a dramatic loss of fluorescence. In this case, the quenching mechanism may be due to a combination of both electron and energy transfer processes. ${ }^{10}$ By contrast, the naphthyl appended macrocycle, $\mathrm{L}^{3}$, when complexed with $\mathrm{Ni}(\mathrm{II})$, shows only a moderate reduction 
in fluorescence intensity that has been ascribed to a Dexter type energy transfer mechanism. ${ }^{7}$ The temperature-dependent lowspin high-spin interconversion of this $\mathrm{Ni}(\mathrm{II})$ complex has been found to affect the efficiency of this mechanism due to changes in the metal's electronic structure, and this system has been proposed as a novel fluorescent thermometer. ${ }^{7}$

The naphthalene and anthracene appended macrocycles (Chart $1, \mathrm{~L}^{1}$ and $\mathrm{L}^{2}$ ) represent a novel variation of these examples where, in this case, the fluorophore has been linked to the macrocycle via an exocyclic primary amine of the parent macrocycle. As a result, it may be anticipated that the coordination tendencies of the macrocyclic (cyclam) core remain essentially unaffected by this synthetic modification, whereas previous work $^{7,11}$ has introduced the chromophore via $\mathrm{N}$ functionalization, introducing a tertiary amine donor that invariably is a poorer donor than its secondary amine neighbors. While the steady-state luminescence spectra of $\mathrm{L}^{1}$ and $\mathrm{L}^{2}$ have been previously reported, ${ }^{12,13}$ herein we report the results of timeresolved and transient measurements that have allowed a much more comprehensive understanding of their behavior.

It is anticipated that these compounds will find application in the growing field of molecular devices (e.g., chemical sensing, photomolecular switching), where precise control over the photophysical response is of paramount importance. Indeed, the $\mathrm{Co}$ (III) complex of a similarly substituted cyclam type macrocycle has been investigated as a model compound for a photoinduced drug delivery system. ${ }^{10}$ Other works have examined the intercalation of $\mathrm{C}$-substituted $\mathrm{Cu}$ (II) cyclam complexes with DNA ${ }^{14}$ or the incorporation of $p$-carboxybenzyl substituted derivatives with protein, ${ }^{15}$ in both cases as a means for metal ion delivery to facilitate radioimmunotherapy or DNA cleavage. An additional primary amine on the periphery of the macrocycle for both $\mathrm{L}^{1}$ and $\mathrm{L}^{2}$ may also allow for the ease of further synthetic modification or the incorporation of additional functional groups.

\section{Experimental Procedures}

Synthesis. The preparation of the photoactive ligands, $\mathrm{L}^{1}$ and $\mathrm{L}^{2}$, has been reported previously. ${ }^{12,13}$ Corresponding $\mathrm{Zn}(\mathrm{II})$ complexes were generated in situ by titration with $\sim 1.1$ equiv of $\mathrm{Zn}\left(\mathrm{ClO}_{4}\right)_{2} \cdot 6 \mathrm{H}_{2} \mathrm{O}$. Unless otherwise stated, all other reagents were obtained commercially and used without further purification.

Physical Methods. Nuclear magnetic resonance spectra were measured at $400.13\left({ }^{1} \mathrm{H}\right)$ and $100.62 \mathrm{MHz}\left({ }^{13} \mathrm{C}\right)$ on a Bruker AV400 spectrometer using a $1: 1 \mathrm{CD}_{3} \mathrm{CN} / \mathrm{CD}_{3} \mathrm{Cl}(\mathrm{v} / \mathrm{v})$ solvent mixture and referenced to the residual $\mathrm{CHD}_{2} \mathrm{CN}$ solvent peak. Electronic absorption spectra were measured on a Perkin-Elmer Lambda 40 spectrophotometer using quartz cells. Steady-state emission and excitation spectra were collected on a Perkin-Elmer LS-50B spectrofluorimeter. Samples were purged with $\mathrm{N}_{2}$ prior to measurements, and cut-off filters were employed to avoid detection of higher order excitation light. Electrochemical measurements were performed using a BAS100B/W potentiostat with a Pt wire auxiliary electrode, $\mathrm{Ag} / \mathrm{Ag}^{+}$nonaqueous reference electrode, and glassy carbon working electrode. All solutions were purged with $\mathrm{N}_{2}$ prior to measurements and contained ca. $5 \times 10^{-3} \mathrm{M}$ analyte with $0.1 \mathrm{M} \mathrm{Et}_{4} \mathrm{NClO}_{4}$ as the supporting electrolyte. Measured potentials were referenced to the ferrocene-ferrocenium couple, which was used as an external standard. X-band $(9.3 \mathrm{GHz})$ continuous wave EPR spectra were recorded on a Bruker ER200 D spectrometer.

Fluorescence lifetimes were determined by time-correlated single photon counting (TCSPC) measurements using an experimental setup similar to that previously described. ${ }^{10}$ An excitation wavelength of $285 \mathrm{~nm}$ was achieved using the frequency doubled output of a cavity-dumped jet stream dye laser (Spectra-Physics, 3500) pumped synchronously by a modelocked $\mathrm{Ar}^{+}$laser (Spectra-Physics, 2030). Rhodamine 6G was used as the dye with the output set to $570 \mathrm{~nm}$ using a threeplate birefringent filter. The laser pulse repetition rate was reduced to $4 \mathrm{MHz}$ through intracavity dumping, and the frequency was doubled in an angle tuned KDP nonlinear crystal providing excitation pulses of $\sim 5 \mathrm{ps}$. Excitation at $390 \mathrm{~nm}$ was performed using the output of a Kerr lens mode-locked Ti:sapphire laser (Coherent, Mira 900f) pumped by a CW $\mathrm{Ar}^{+}$ laser (Coherent, Innova 400) as the light source. The repetition rate of the $130 \mathrm{fs}$ duration pulses from the Ti:sapphire laser was reduced to $4 \mathrm{MHz}$ with a home-built pulse picker based on a $\mathrm{TeO}_{2}$ Bragg cell and CAMAC driver, and subsequently, the frequency was doubled in a BBO nonlinear crystal. Solution concentrations were $\sim 10^{-5} \mathrm{M}$ in analyte, which, if necessary, were further diluted to maintain an optical density of no more than 0.1 at the excitation wavelength, and samples were degassed thoroughly by purging with $\mathrm{N}_{2}$ prior to each measurement. Data collection was performed as previously described ${ }^{10}$ yielding a full width at half-maximum (fwhm) for the instrument response function (IRF) of less than 200 ps. Observed fluorescence time profiles were analyzed by iterative reconvolution with the measured instrument response functions using a nonlinear least-squares fitting procedure based on the Marquardt-Levenberg algorithm using a commercially available software package (Picoquant, FluoFit v3.1.0). Goodness of fit was assessed by minimizing the reduced chi squared function, $\chi^{2}$, and a visual inspection of the weighted residuals. Support plane error analysis was performed with a $2.5 \%$ confidence interval on the reduced $\chi^{2}$ function.

The fluorescence upconversion setup was based on the commercially available FOG100 system (CDP, Laser \& Scanning Systems) and has been described in detail previously. ${ }^{16}$ An excitation wavelength of $395 \mathrm{~nm}$ was achieved using the frequency doubled output of a Kerr lens mode-locked Ti:sapphire laser (Tsunami, Spectra-Physics) with the fundamental tuned to $790 \mathrm{~nm}$. The full width at half-maximum (fwhm) of the instrument response function (IRF) for this setup was ca. 210 fs. Fluorescence time profiles were analyzed using a nonlinear least-squares fitting procedure.

The experimental setup used to perform picosecond multiplex transient grating experiments has been described in detail elsewhere. ${ }^{17,18}$ Excitation (pump pulse) was achieved with the third harmonic output at $355 \mathrm{~nm}$ of an active/passive modelocked Q-switched Nd:YAG laser with a single amplification stage (Continuum, PY61-10). The duration of the pulses was about $25 \mathrm{ps}$, and the pump intensity on the sample was of the order of $2 \mathrm{~mJ} / \mathrm{cm}^{2}$. The time resolution of this setup was $30 \mathrm{ps}$.

Molecular modeling of the $\mathrm{Zn}(\mathrm{II})$ complexes of $\mathrm{L}^{1}$ and $\mathrm{L}^{2}$ was performed with MOMEC $97^{19}$ using previously reported force field parameters ${ }^{20}$ to evaluate the likely solution conformations of these two molecules. Drawings of modeled structures were produced with RASMOL. ${ }^{21,22}$

\section{Results}

Steady-State Photophysics. The absorption spectra of the free ligands and their corresponding $\mathrm{Zn}$ (II) complexes (Supporting Information, Figures S1 and S2) are essentially identical and are characteristic of the appended fluorophore in each case. For $\mathrm{L}^{1}$ and $\left[\mathrm{ZnL}^{1}\right]^{2+}$, the spectra are dominated by intense absorptions in the UV, the first appearing as a poorly resolved 


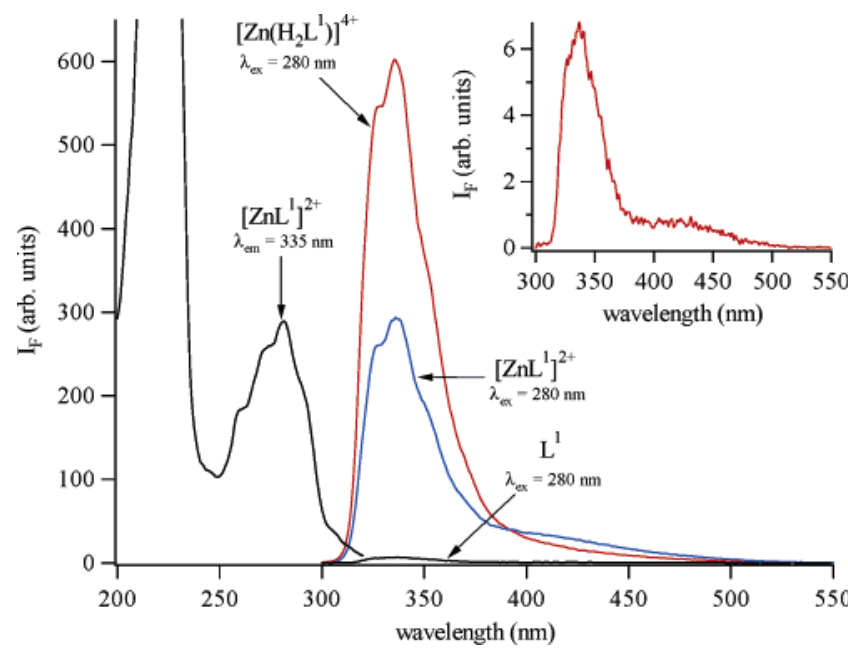

Figure 1. Emission and excitation spectra of $\mathrm{L}^{1},\left[\mathrm{ZnL}^{1}\right]^{2+}$, and $[\mathrm{Zn}$ $\left.\left(\mathrm{H}_{2} \mathrm{~L}^{1}\right)\right]^{4+}$ in $\mathrm{CH}_{3} \mathrm{CN}$ at $298 \mathrm{~K}$. Inset: expansion of $\mathrm{L}^{1}$ emission showing the exciplex band at $\sim 420 \mathrm{~nm}$.

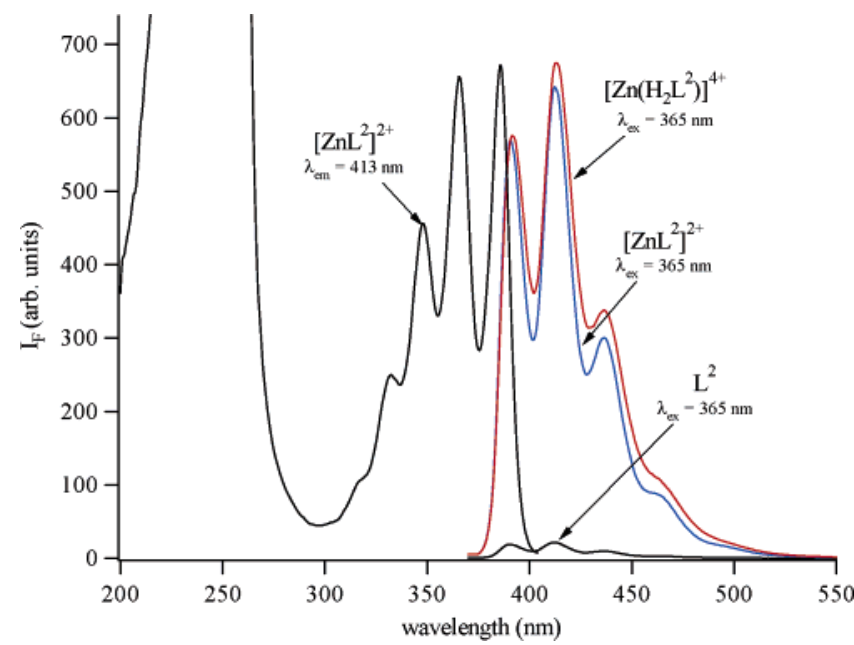

Figure 2. Emission and excitation spectra of $\mathrm{L}^{2},\left[\mathrm{ZnL}^{2}\right]^{2+}$, and $[\mathrm{Zn}$ $\left.\left(\mathrm{H}_{2} \mathrm{~L}^{2}\right)\right]^{4+}$ in $\mathrm{CH}_{3} \mathrm{CN}$ at $298 \mathrm{~K}$.

vibrational progression centered at ca. $281 \mathrm{~nm}$ and the second as an intense band at $223 \mathrm{~nm}$. By reference to the parent chromophore, ${ }^{23}$ these have been assigned to the $S_{0} \rightarrow S_{2}$ and $\mathrm{S}_{0} \rightarrow \mathrm{S}_{3}$ electronic transitions, respectively, with the former exhibiting vibronic coupling to aromatic ring breathing modes of the naphthalene chromophore. Similarly, for $\mathrm{L}^{2}$ and $\left[\mathrm{ZnL}^{2}\right]^{2+}$, there are two strong absorptions in the UV region. The first of these bands appears at $385 \mathrm{~nm}$ as a well-resolved vibrational progression with peaks separated by ca. $1400 \mathrm{~cm}^{-1}$ and has been assigned to the anthracene $\mathrm{S}_{0} \rightarrow \mathrm{S}_{1}$ transition, ${ }^{23}$ with the additional vibrational structure due to vibronic coupling with aromatic ring breathing modes of the chromophore. At higher energy, a very intense second band assigned to the $S_{0} \rightarrow S_{3}$ transition was evident at $254 \mathrm{~nm}$.

The emission spectra of $\mathrm{L}^{1}, \mathrm{~L}^{2}$, and their corresponding $\mathrm{Zn}$ (II) complexes in $\mathrm{CH}_{3} \mathrm{CN}$ solution are shown in Figures 1 and 2 respectively, with the latter in agreement with that previously reported. ${ }^{12}$ Also shown are the excitation spectra of the $\mathrm{Zn}$ (II) complexes and emission spectra of their diprotonated adducts, $\left[\mathrm{Zn}\left(\mathrm{H}_{2} \mathrm{~L}^{1}\right)\right]^{4+}$ and $\left[\mathrm{Zn}\left(\mathrm{H}_{2} \mathrm{~L}^{2}\right)\right]^{4+}$, which were generated by the addition of 2 molar equiv of trifluoroacetic acid solution (TFA). For $\mathrm{L}^{1}$, the emission spectrum consisted of a very weak band, displaying significant vibrational structure, with a maximum at ca. $335 \mathrm{~nm}$ and a quantum yield of $0.047( \pm 5 \%)$ as determined by the optically dilute method ${ }^{24}$ with reference to the parent naphthalene chromophore $\left(\Phi_{\mathrm{F}}=0.42\right) .{ }^{25}$ Also evident in the emission spectrum of $\mathrm{L}^{1}$ was a broad featureless band to lower energy centered at ca. $420 \mathrm{~nm}$ assigned to emission from a charge-transfer exciplex. ${ }^{26}$ Upon complexation with $\mathrm{Zn}(\mathrm{II})$, the emission from the naphthalene chromophore shows a dramatic increase in fluorescence quantum yield to $0.29( \pm 5 \%)$. The corresponding excitation spectrum monitored at the emission maximum $\left(\lambda_{\mathrm{em}}=335 \mathrm{~nm}\right)$ is also shown in Figure 1 and was found to essentially follow the electronic absorption spectrum. Lastly, upon diprotonation of the $\mathrm{Zn}$ (II) complex, the fluorescence increases further with a final quantum yield of 0.53 $( \pm 5 \%)$ and minor changes to the band shape of the emission, most notably a loss of the long wavelength exciplex emission $\left(\lambda_{\mathrm{em}}>390 \mathrm{~nm}\right)$. As previously reported, ${ }^{12}$ the emission of $\mathrm{L}^{2}$ was quite weak, with an electronic origin at ca. $390 \mathrm{~nm}$ and several well-resolved vibrational bands to lower energy with a maximum intensity at $413 \mathrm{~nm}$. The fluorescence quantum yield was determined to be $0.006( \pm 5 \%)$ by comparison to the parent chromophore. ${ }^{24}$ As with the naphthyl system, the $\left[\mathrm{ZnL}^{2}\right]^{2+}$ complex displayed a pronounced revival of fluorescence intensity with an increased fluorescence quantum yield of $0.19( \pm 5 \%)$ upon complexation. However, by contrast to $\left[\mathrm{ZnL}^{1}\right]^{2+}$, the addition of 2 molar equiv of TFA to a solution of $\left[\mathrm{ZnL}^{2}\right]^{4+}$ resulted in only a minimal increase in fluorescence intensity for the ensuing $\left[\mathrm{Zn}\left(\mathrm{H}_{2} \mathrm{~L}^{2}\right)\right]^{4+}$ complex.

Time-Resolved Photophysics. Time-resolved fluorescence decay profiles for $\mathrm{L}^{1}$ and $\mathrm{L}^{2}$ were measured by the TCSPC technique in $\mathrm{CH}_{3} \mathrm{CN}$ solution. In both cases, the fluorescence decays could not be satisfactorily fit by either a single or biexponential decay function. Rather, a triple exponential decay model was required to achieve a satisfactory fit. By contrast, the time-resolved fluorescence decays collected for the corresponding $\mathrm{Zn}$ (II) complexes of $\mathrm{L}^{1}$ and $\mathrm{L}^{2}$ were well-represented by a simpler biexponential decay model. The resulting fit parameters for both the free ligands and their $\mathrm{Zn}(\mathrm{II})$ complexes are summarized in Table 1. Notably, while the deactivation kinetics of the $\mathrm{Zn}$ (II) complexes were measurable on the nanosecond time scale, for the free ligand cases, the major decay components have lifetimes on the picosecond time scale, indicating very rapid nonradiative deactivation of the excited state. This prompted further characterization of $\mathrm{L}^{2}$ utilizing fluorescence upconversion techniques. The resulting fluorescence decay curve (Supporting Information, Figure S3) also showed multiexponential decay behavior. In principle, this could be reproduced with a biexponential decay function that plateaus to a nonzero value. However, from TCSPC measurements, we know this plateau in fact arises from the presence of slower decaying components, which are imperceptible on the picosecond time scale. Hence, the data were fit to a four exponential decay function with two lifetimes fixed to the values obtained from TCSPC measurements in the same mixed solvent system $\left(\tau_{1}=170 \mathrm{ps}(30 \%), \tau_{2}=2.0 \mathrm{~ns}(7 \%)\right)$ and two that were allowed to vary $\left(\tau_{3}=0.75 \pm 0.04 \mathrm{ps}(19 \%), \tau_{4}=12.0 \pm 0.6\right.$ ps $(44 \%))$.

As a further probe of the excited-state deactivation pathways and photophysics for $\mathrm{L}^{2}$ and its corresponding $\mathrm{Zn}$ (II) complex, picosecond multiplex transient grating measurements were performed. The resulting transient grating spectra for the free ligand, $\mathrm{L}^{2}$, are shown in Figure 3. As discussed in detail elsewhere, ${ }^{17,18}$ these spectra are very similar to transient absorption spectra, the main difference being that the transient grating intensity is always positive. The spectra are composed primarily of a major peak at ca. $600 \mathrm{~nm}$, which rapidly decays with time and a slightly smaller, broad absorption centered at 
TABLE 1: Fluorescence Decay Parameters of $\mathrm{L}^{1},\left[\mathrm{ZnL}^{1}\right]^{2+}, \mathrm{L}^{2}$, and $\left[\mathrm{ZnL}^{2}\right]^{2+}$ in $\mathrm{CH}_{3} \mathrm{CN}$ Solution at $298 \mathrm{~K}$ Determined by TCSPC Measurements

\begin{tabular}{|c|c|c|c|c|c|c|c|}
\hline system & decay time $\tau_{1}(\mathrm{~ns})$ & amplitude $A_{1}(\%)$ & decay time $\tau_{2}(\mathrm{~ns})$ & amplitude $\mathrm{A}_{2}(\%)$ & decay time $\tau_{3}(\mathrm{~ns})$ & amplitude $A_{3}(\%)$ & $\begin{array}{l}\text { goodness of } \\
\text { fit } \chi^{2} \text { (reduced) }\end{array}$ \\
\hline$\overline{\mathrm{L}^{1}}$ & $0.066^{a} \pm 0.008$ & $64 \pm 8.3$ & $1.08 \pm 0.04$ & $30 \pm 0.5$ & $5.85 \pm 0.57$ & $6 \pm 0.5$ & 1.71 \\
\hline$\left[\mathrm{ZnL}^{1}\right]^{2+}$ & $3.34 \pm 0.12$ & $69 \pm 1.3$ & $10.44 \pm 0.54$ & $31 \pm 2.9$ & N/A & N/A & 4.53 \\
\hline $\mathrm{L}^{2}$ & $0.039^{a} \pm 0.004$ & $83 \pm 7.7$ & $0.997 \pm 0.11$ & $10 \pm 1.1$ & $2.64 \pm 0.28$ & $7 \pm 1.3$ & 1.22 \\
\hline$\left[\mathrm{ZnL}^{2}\right]^{2+}$ & $2.21 \pm 0.05$ & $89 \pm 1.2$ & $7.78 \pm 0.66$ & $11 \pm 1.4$ & N/A & N/A & 1.54 \\
\hline
\end{tabular}

${ }^{a}$ Less than full width at half-maximum (fwhm) of instrument response function (IRF).
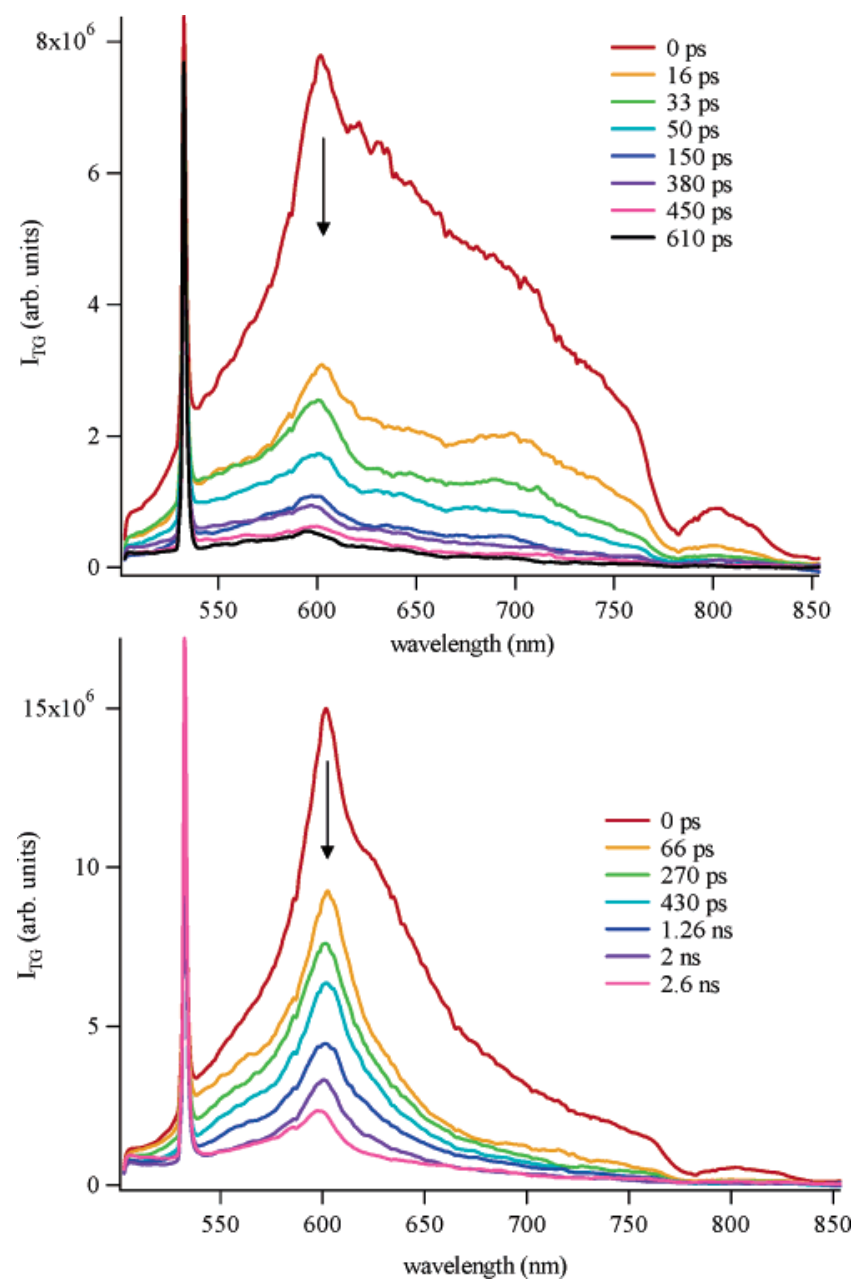

Figure 3. Transient grating spectra of $\mathrm{L}^{2}$ (top) and $\left[\mathrm{ZnL}^{2}\right]^{2+}$ (bottom) in $1: 1(\mathrm{v} / \mathrm{v}) \mathrm{CH}_{3} \mathrm{CN} /$ toluene at $298 \mathrm{~K}$ with $355 \mathrm{~nm}$ excitation. The 532 nm spikes are due to the second harmonic of the Nd:YAG laser pulses.

ca. $700 \mathrm{~nm}$. By reference to the literature, ${ }^{27,28}$ the former band can be assigned to the locally excited anthracene excited-state singlet-singlet absorptions, $\mathrm{S}_{1} \rightarrow \mathrm{S}_{n}$, and the decay kinetics of this band were well-reproduced by a fitting of the results to the major components from fluorescence upconversion and TCSPC measurements in the same solvent system. The $700 \mathrm{~nm}$ band can be similarly assigned to absorption by the anthracene radical anion. ${ }^{29}$ Importantly, the observed intensity of this band is quite small. Moreover, the decay kinetics are more rapid than the corresponding $600 \mathrm{~nm}$ band, as demonstrated by the negligible intensity at longer time delay, indicating that the rate of charge recombination for the radical anion is faster than that of charge separation. Figure 3 also shows the TG spectra for the corresponding $\mathrm{Zn}(\mathrm{II})$ complex of $\mathrm{L}^{2}$. Here, it can be seen the spectra consist of a single band at ca. $600 \mathrm{~nm}$ that, by analogy to the free ligand, has been ascribed to locally excited anthracene $\mathrm{S}_{1} \rightarrow \mathrm{S}_{n}$ absorption and displayed decay kinetics that agreed with those obtained from TCSPC measurements. Notably, the

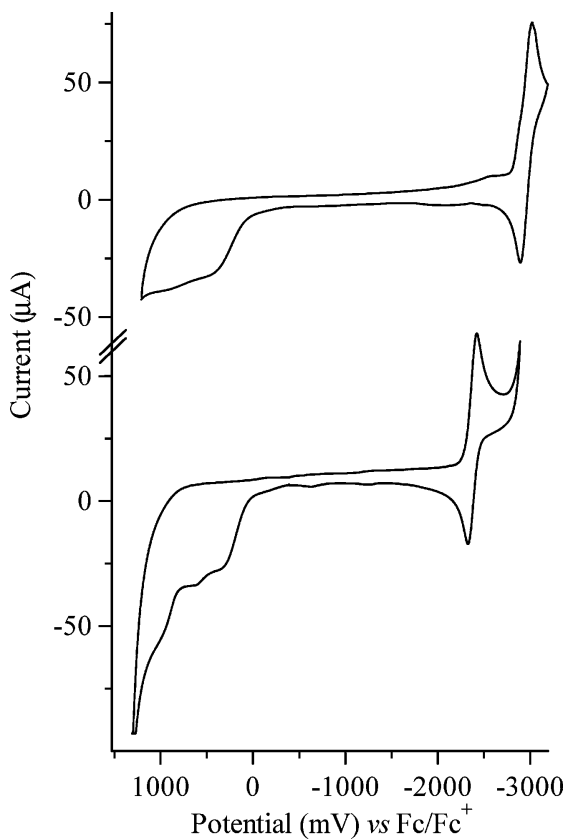

Figure 4. Cyclic voltammetry of $\mathrm{L}^{1}$ (top) and $\mathrm{L}^{2}$ (bottom) in DMF at $298 \mathrm{~K}$.

broad peak associated with absorption by the anthracene radical anion is absent in spectra for the $\mathrm{Zn}$ (II) complex.

EPR Spectroscopy. Observation of the anthracene radical anion spectrum by transient grating techniques prompted further characterization of $\mathrm{L}^{1}$ and $\mathrm{L}^{2}$ by electron paramagnetic resonance (EPR). The free ligands displayed no detectable radical signals under ambient conditions. However, when illuminated with a UV light source (Hg lamp), a very weak signal was observed (see Supporting Information, Figure S4). The observed signal was a triplet, which identified it as an $\mathrm{N}$ centered radical, with a hyperfine coupling $\left(a^{\mathrm{N}} \sim 15.0 \mathrm{G}\right)$ to the ${ }^{14} \mathrm{~N}(I=1)$ nucleus. Hence, this signal was ascribed to an $\mathrm{N}$-based radical cation, which is a product of the PET quenching reaction.

Electrochemistry. Electrochemical measurements were performed by cyclic voltammetry in DMF, which offered both enhanced solubility and an improved reducing potential range as compared to $\mathrm{CH}_{3} \mathrm{CN}$. The resulting voltammograms for $\mathrm{L}^{1}$ and $\mathrm{L}^{2}$ are shown in Figure 4. Both systems display a single reversible wave in the reductive sweep corresponding to reduction of the appended fluorophore. For $\mathrm{L}^{1}$, this wave appears at ca. $-2950 \mathrm{mV}$ versus $\mathrm{Fc}^{+/ 0}$, which is comparable to literature values for the corresponding process in naphthalene. ${ }^{30}$ For $\mathrm{L}^{2}$, the anthracene radical anion wave appears at ca. $-2400 \mathrm{mV}$ versus $\mathrm{Fc}^{+/ 0}$, which agrees well with that of 9-methylanthracene measured under the same conditions $\left(-2420 \mathrm{mV}\right.$ vs $\left.\mathrm{Fc}^{+/ 0}\right)$.

In the oxidative sweep, very broad nonreversible responses were observed for both systems, with potentials ranging from ca. +200 to $+1000 \mathrm{mV}$. These have been ascribed to amine lone pair oxidation processes, by comparison to the behavior of the parent macrocycle under the same conditions. ${ }^{12}$ Lastly, 
CHART 2: Four Tetradentate N-Based Isomeric Forms of the $\left[\mathrm{ZnL}^{1}\right]^{2+}$ and $\left[\mathrm{ZnL}^{2}\right]^{2+}$ Complexes and Their Potential Pentadentate and Hexadentate Forms
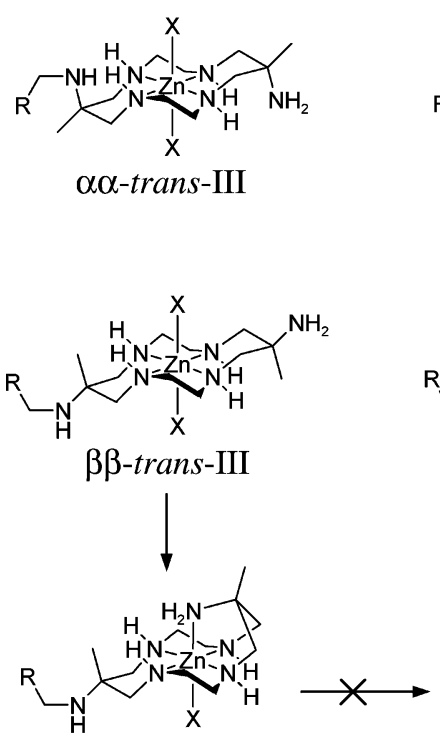
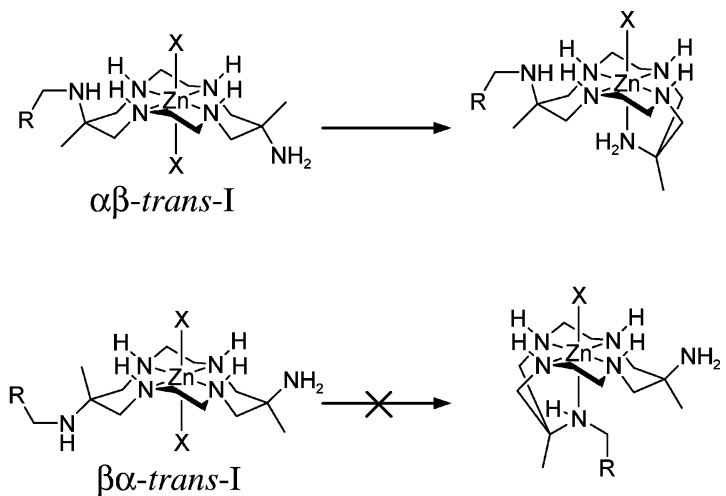

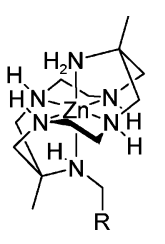

the onset of an additional, poorly resolved response in the voltammogram of $\mathrm{L}^{2}$ was observed at a potential of ca. +1000 $\mathrm{mV}$, which may be due to anthracene radical cation formation by analogy to the same process in the parent anthracene (ca. $1100 \mathrm{mV}) .^{12}$

Monitoring Zn(II) Complexation by ${ }^{1} \mathrm{H}$ NMR. By comparison with the reported ${ }^{31}$ structure of the parent macrocycle complexed with $\mathrm{Zn}(\mathrm{II})$, it was initially envisaged the complexation of $\mathrm{L}^{1}$ and $\mathrm{L}^{2}$ with an appropriate $\mathrm{Zn}$ (II) salt may yield the hexadentate coordinated complex shown in Chart 2. As such, the reactions of $\mathrm{L}^{1}$ and $\mathrm{L}^{2}$ with $\mathrm{Zn}\left(\mathrm{ClO}_{4}\right)_{2} \cdot 6 \mathrm{H}_{2} \mathrm{O}$ were studied by ${ }^{1} \mathrm{H}$ NMR in a $1: 1(\mathrm{v} / \mathrm{v}) \mathrm{CD}_{3} \mathrm{CN} / \mathrm{CDCl}_{3}$ solvent mixture by titrating a known equivalent of metal ion into a solution of the ligand. The resulting spectra are shown in Figure 5, where the effects of $\mathrm{Zn}$ (II) addition were monitored. For both $\mathrm{L}^{1}$ and $\mathrm{L}^{2}$, complexation of the ligand was verified by observing shifts in the ${ }^{1} \mathrm{H}$ NMR resonances of the free ligand, and in addition, a 1:1 stoichiometry of the ensuing complexes was confirmed. Importantly, however, the complexation reaction does not progress cleanly to give a single product. Rather, the appearance of multiple sets of proton resonances was observed, which we attribute to the formation of differing N-based isomers of the complex in solution. Unfortunately, because of the accidental degeneracy of several peaks, the ${ }^{1} \mathrm{H}$ NMR spectrum cannot be unambiguously assigned, particularly in the upfield methyl region where multiple resonances occur. However, in both cases, the deshielded methyl peak, corresponding to the group adjacent to the aromatic chromophore, was transformed upon complexation into two smaller, sharp singlets, indicative of only two major isomers in solution. Moreover, the linking methylene resonances at ca. $4.2 \mathrm{ppm}$ for $\left[\mathrm{ZnL}^{1}\right]^{2+}$ and ca. $4.7 \mathrm{ppm}$ for $\left[\mathrm{ZnL}^{2}\right]^{2+}$ appear as two distinguishable singlet peaks, similarly indicating the presence of two major forms of the complex. Lastly, the singlet multiplicity of these methylene linker resonances indicates that the adjacent secondary amine is not coordinated to the metal, otherwise the protons of the methylene linker would be split into an $\mathrm{AB}$ quartet due to the chemical inequivalence, and rigidity that would be induced by complexation.

Molecular Modeling. Analysis of the N-based isomeric ensemble formed upon complexation of $\mathrm{L}^{1}$ and $\mathrm{L}^{2}$ with $\mathrm{Zn}$ (II) was considered of paramount importance to allow meaningful insights into the $\mathrm{Zn}$ (II) complex photophysics to be drawn. As such, the possible solution conformations of these complexes were assessed by molecular modeling calculations. Briefly, as shown in Chart 2, either tetradentate or pentadentate coordination modes for each ligand were considered since ${ }^{1} \mathrm{H}$ NMR evidence excluded the hexadentate form. In the first case, a tetragonally elongated octahedral coordination environment about the metal ion was assumed, with four $\mathrm{N}$-donors provided by tetradentate coordination of the macrocycle in the common
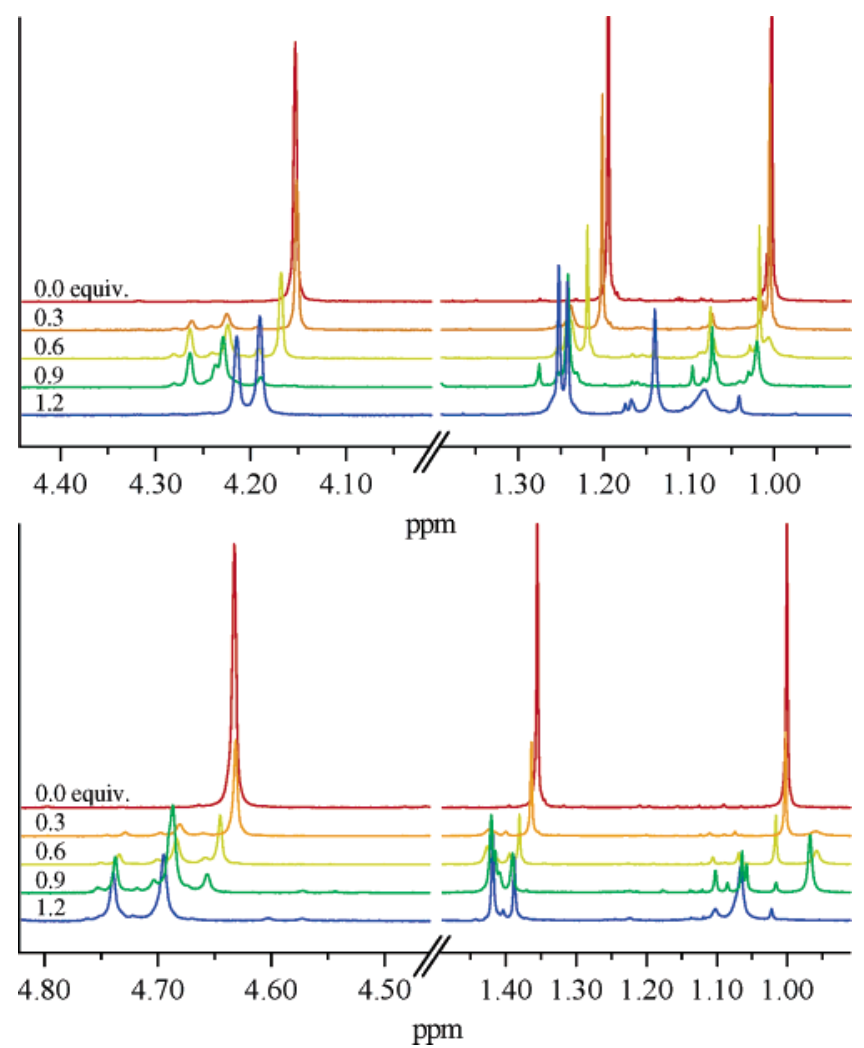

Figure 5. ${ }^{1} \mathrm{H}$ NMR spectra of $\mathrm{L}^{1}$ (top) and $\mathrm{L}^{2}$ (bottom) in $1: 1(\mathrm{v} / \mathrm{v})$ $\mathrm{CD}_{3} \mathrm{CN} / \mathrm{CDCl}_{3}$ upon addition of $\mathrm{Zn}\left(\mathrm{ClO}_{4}\right)_{2} \cdot 6 \mathrm{H}_{2} \mathrm{O}(0.0,0.3,0.6,0.9$, and 1.2 equiv) showing the methyl and methylene linker regions. 
TABLE 2: Summary of Results from Molecular Modeling Studies of the Various Possible N-Based Isomers of $\left[\mathrm{ZnL}^{1}\right]^{2+}$ and $\left[\mathrm{ZnL}^{2}\right]^{2+}$

\begin{tabular}{lcc}
\hline N-based isomer & \multicolumn{2}{c}{ minimized strain energy ${ }^{a}\left(\mathrm{~kJ} \mathrm{~mol}^{-1}\right)$} \\
\cline { 2 - 3 } \multicolumn{1}{c}{ tetradentate } & {$\left[\mathrm{ZnL}^{1}\right]^{2+}$} & {$\left[\mathrm{ZnL}^{2}\right]^{2+}$} \\
\hline $\mathrm{N}_{4}-\alpha \alpha$-trans-III & 64.29 & 81.97 \\
$\mathrm{~N}_{4}-\beta \beta$-trans-III & 81.37 & 103.20 \\
$\mathrm{~N}_{4}-\alpha \beta$-trans-I & 82.55 & 101.53 \\
$\mathrm{~N}_{4}-\beta \alpha$-trans-I & 92.34 & 114.04 \\
pentadentate & & \\
$\mathrm{N}_{5}-\beta \beta$-trans-III & 100.38 & 121.51 \\
$\mathrm{~N}_{5}-\alpha \beta$-trans-I & 88.83 & 109.61 \\
${ }^{a}$ Of lowest energy (global) minima. &
\end{tabular}

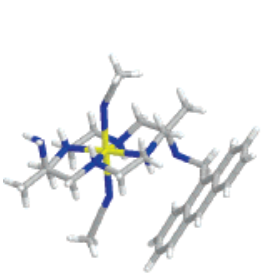

$\mathrm{N}_{4}-\alpha \alpha$-trans-III

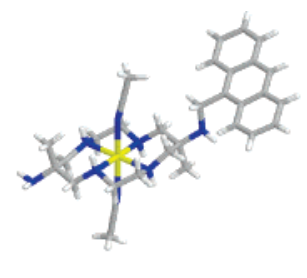

$\mathrm{N}_{4}-\beta \beta$-trans-III

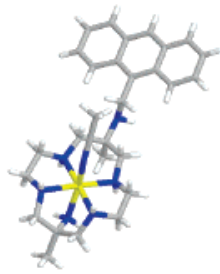

$\mathrm{N}_{\mathrm{s}}-\beta \beta$-trans-III

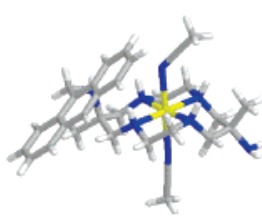

$\mathrm{N}_{4}-\alpha \beta$-trans-I

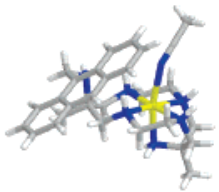

$\mathrm{N}_{5}-\alpha \beta$-trans-I
$\mathrm{N}_{4}-\beta \alpha$-trans-I

Figure 6. Strain energy minimized structures obtained from molecular modeling of various possible $\mathrm{N}$-based isomeric forms of $\left[\mathrm{ZnL}^{2}\right]^{2+}$.

trans-III and trans-I isomeric forms ${ }^{32}$ to give an equatorial $\mathrm{N}_{4}$ plane. Two solvent $\mathrm{CH}_{3} \mathrm{CN}$ molecules, bound in axial positions, were modeled to complete the first coordination sphere by reference to crystallographic data. ${ }^{33,34}$ Alternatively, pentadentate coordination modes of the macrocycles were considered, as observed in Co(III) complexes of structurally similar ligands, ${ }^{35}$ with the additional $\mathrm{N}$ donor atom provided by coordination of the unsubstituted primary amine and a single axial solvent molecule. The results of these calculations are summarized in Table 2, and the resulting strain energy minimized structures for $\left[\mathrm{ZnL}^{2}\right]^{2+}$ are shown in Figure 6. On the basis of these strain energies, the tetradentate $\alpha \alpha$-trans-III isomer of either $\mathrm{L}^{1}$ or $\mathrm{L}^{2}$ coordinated to $\mathrm{Zn}(\mathrm{II})$ is the favored conformer, due to the alternating chair and gauche conformations of the six and fivemembered chelate rings, respectively. ${ }^{32}$ The minimized strain energy for this conformation was found to be some $20 \mathrm{~kJ} \mathrm{~mol}^{-1}$ lower than any of the other N-based isomers. Moreover, it is invariably this $\mathrm{N}$-based isomer that has been observed crystallographically for many $\mathrm{Zn}$ (II) derivatives of cyclam (i.e., transIII),${ }^{33,34}$ the parent macrocycle, ${ }^{31}$ and its functionalized derivatives. ${ }^{36,37}$

\section{Discussion}

The absorption spectra of the free ligands and their corresponding $\mathrm{Zn}$ (II) complexes are essentially identical and show absorption features of the appended aromatic group alone. The only notable feature was a slight bathochromic shift of the electronic transitions relative to naphthalene and anthracene, which can be attributed to alkylation of the chromophore, as has been observed previously. ${ }^{38}$ As mentioned in preliminary steady-state investigations of $\mathrm{L}^{1}$ and $\mathrm{L}^{2}$, the emissive behavior at low temperature led to a postulated reductive quenching of the photoexcited fluorophore at room temperature by a photoinduced electron-transfer mechanism involving the proximate amine donors. ${ }^{12,13}$ An inspection of the emission spectra and fluorescence quantum yields for $\mathrm{L}^{1}$ and $\mathrm{L}^{2}$ unequivocally illustrates the presence of this quenching mechanism in both systems.

The thermodynamic favorability for a given PET reaction may be estimated by use of the Rehm-Weller relationship ${ }^{39}$

$$
\Delta G^{\circ}(\mathrm{eV})=E^{\circ}\left(\mathrm{D}^{+} / \mathrm{D}^{-}\right)-E^{\circ}\left(\mathrm{A} / \mathrm{A}^{-}\right)-\Delta E_{00}-w_{\mathrm{p}}
$$

where $E^{\circ}\left(\mathrm{D}^{+} / \mathrm{D}\right)$ is the standard redox potential for oxidation of the donor, $E^{\circ}\left(\mathrm{A} / \mathrm{A}^{-}\right)$is the standard redox potential for reduction of the acceptor, $\Delta E_{00}$ is the energy of the excited state for the photoactive component (in $\mathrm{eV}$ ), and $w_{\mathrm{p}}$ is the Coulombic work term. In the present instance, several issues complicate an analysis of this type. First, there exist several potential amine nitrogen donors, each of which may contribute to the overall quenching effect to differing extents. As a result, the exact separation between the charge separated product, and hence the Coulombic work term, cannot be well-defined. Second, the illresolved amine oxidation waves determined by cyclic voltammetry preclude accurate determination of their redox potentials. Nonetheless, by neglecting the Coulombic work term and using a conservative estimate of the amine oxidation potential of ca. $+300 \mathrm{mV}$ versus $\mathrm{Fc}^{+/ 0}$, the free energy change may be estimated as ca. -0.63 and $-0.48 \mathrm{eV}$ for $\mathrm{L}^{1}$ and $\mathrm{L}^{2}$, respectively. Clearly, in both cases, the PET reaction is exergonic. Indeed, the occurrence of this reaction is borne out by spectroscopic investigations, which also illustrate the products of this PET quenching pathway. For both $\mathrm{L}^{1}$ and $\mathrm{L}^{2}$, the appearance of an N-based radical cation EPR signal, only under UV illumination, is direct evidence for the photoinduced quenching process. The additional observation of an anthracene radical anion absorption for $\mathrm{L}^{2}$ via transient grating methods strengthens the case.

Analysis of the rapid decay of the locally excited singlet excited-state population, as determined by TCSPC studies, allows further insight into the dynamics of the PET quenching reaction. As shown in Table 1, the fluorescence decay profiles of the free ligands were multiexponential, requiring at least triple exponential fits, with the major decay component determined to be less than the time resolution of the TCSPC experiment. Subsequent fluorescence upconversion measurements for $\mathrm{L}^{2}$ revealed that this rapid decay itself comprises two components, and the behavior of $\mathrm{L}^{1}$ may be expected to be similar. This multiexponential decay behavior can best be rationalized in terms of differing solution conformations rather than a single conformer quenched to varying extents by differing $\mathrm{N}$-donor atoms, although the involvement of several macrocyclic amines as PET donor atoms is exemplified by the observation that sequential addition of $\mathrm{H}^{+}$, in the form of an organic acid such as trifluoroacetic acid (TFA), to a solution of either the $\mathrm{L}^{1}$ or $\mathrm{L}^{2}$ results in a gradual rise in fluorescence intensity, which plateaus after 4 molar equiv. ${ }^{12,13}$ In any case, a single conformer would display a single-exponential decay with an observed fluorescence lifetime equal to the inverse sum of all deactivation rate constants.

Considering the flexibility of the free macrocycle, which may be regarded as a substituent of the fluorophore, it is easy to envisage many possible conformations, each with differing amine-fluorophore separations, which would support the experimentally observed multiexponential decay behavior. It is 


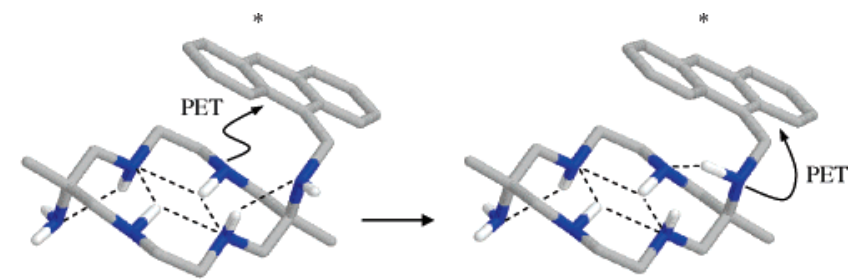

Figure 7. Intramolecular hydrogen bonding network common to derivatives of the parent macrocycle. Pyramidal inversion of substituted pendant amine with subsequent alteration of PET donor and quenching kinetics.

well-known that a distribution of decay times due to a distribution of conformations can often give rise to a decay that can be reproduced by a bi- or triexponential function. ${ }^{40,41}$ Additionally, a consideration of the intramolecular hydrogen bonding within the macrocycle may yield further insight. Crystallographically, a network of intramolecular H-bonds is often observed in derivatives of the parent macrocycle, ${ }^{42,37}$ resulting in a well-defined conformation mimicking that seen upon metal ion coordination as shown in Figure 7. Herein, we see several bifurcated hydrogen bonding interactions between alternate macrocyclic secondary amine protons and lone pairs that form a quadrilateral arrangement at the center of the macrocycle. Additionally, the protons (or the lone pairs) of the exocyclic amines also display an interaction with the remaining lone pairs (or protons) not involved in this motif. It is reasonable to assume that this pattern is maintained at least to some extent in solution, particularly in aprotic solvents such as acetonitrile. Since electronic motions are orders of magnitude faster than nuclear vibrations, the involvement of an amine lone pair as a PET electron donor will be dependent on the degree and strength of hydrogen bonding. Particularly for the pendant amine, pyramidal inversion will drastically alter this network as illustrated by Figure 7, and subsequently, the rate of PET should also be strongly influenced by the configuration of these centers.

The fluorescence behavior observed for $\mathrm{L}^{1}$ and $\mathrm{L}^{2}$ when complexed to $\mathrm{Zn}$ (II) is further evidence of the PET quenching mechanism operant within the free ligands. Upon coordination, the macrocyclic amines are protected from photoinduced oxidation, and the characteristic fluorescence of the chromophore is greatly enhanced. In light of the results from the ${ }^{1} \mathrm{H}$ NMR $\mathrm{Zn}$ (II) complexation titrations and molecular modeling of the $\mathrm{Zn}$ (II) complex solution conformations, a particularly vexing question arose. Namely, are the noncoordinated exocyclic amines photoactive? This question may be resolved by an inspection of the fluorescence spectra for $\left[\mathrm{Zn}\left(\mathrm{H}_{2} \mathrm{~L}^{1}\right)\right]^{4+}$ and $\left[\mathrm{Zn}\left(\mathrm{H}_{2} \mathrm{~L}^{2}\right)\right]^{4+}$ (Figures 1 and 2), which were generated by the addition of 2 molar equiv of trifluoroacetic acid (TFA) to solutions of the corresponding $\mathrm{Zn}$ (II) complexes. This protonation was also monitored separately by ${ }^{1} \mathrm{H}$ NMR spectroscopy (data not shown) and results in significant downfield shifts for several resonances, particularly those of the methylene linker adjacent to the second protonation site (e.g., $\left[\mathrm{ZnL}^{2}\right]^{2+} \sim 4.70$ $\rightarrow \sim 5.25 \mathrm{ppm}$ ). Subsequent addition of an equimolar aliquot of base $\left(\mathrm{Et}_{3} \mathrm{~N}\right.$ or $\left.\mathrm{NaOH}\right)$ was found to regenerate the unprotonated species, with a corresponding restoration of the methylene resonance chemical shift, indicating the process to be reversible, with no degradation of the complex. For $\left[\mathrm{ZnL}^{2}\right]^{2+}$, the addition of TFA had little effect on the overall fluorescence quantum yield of the anthracene chromophore. By contrast, the addition of 2 equiv of TFA to a solution of the $\left[\mathrm{ZnL}^{1}\right]^{2+}$ results in a significant increase in fluorescence intensity. This result may be interpreted as follows. For $\left[\mathrm{ZnL}^{2}\right]^{2+}$, the relative insensitivity of anthracene emission to the protonation state of the pendant amines suggest that even when in their unprotonated or uncoordinated form, the $\mathrm{Zn}$ (II) cation induces a significant inductive effect on the ionization potential of the amine. Incorporation of the metal cation within the macrocycle, as expected, renders the macrocyclic secondary amine nitrogens inert to oxidation. In other words, the formation of an amine radical cation becomes more difficult with a proximal $\mathrm{Zn}$ (II) cation due to electrostatic repulsion. For the $\left[\mathrm{ZnL}^{1}\right]^{2+}$ complex, by contrast, it emerges that the pendant amines must still be involved in quenching the excited state of the naphthalene chromophore to a significant extent via a reductive PET mechanism, as protonation results in significant fluorescence enhancement.

Thermodynamically, the difference in photoactivity may be rationalized by a qualitative consideration of the corresponding acceptor reduction potentials and the spectroscopic zero point energy (pure electronic origin) of the fluorophore excited states. For the naphthalene based system, $\mathrm{L}^{1}$, the overall free energy change associated with the PET reaction in the free ligand $(-0.63 \mathrm{eV})$ was calculated to be some $0.15 \mathrm{eV}$ more exergonic than the corresponding reaction with anthracene as the fluorophore $(-0.48 \mathrm{eV})$, demonstrating that the naphthalene excited state is a stronger oxidant. Hence, the difference in photoactivity of the $\mathrm{Zn}$ (II) complexes of $\mathrm{L}^{1}$ and $\mathrm{L}^{2}$ may be rationalized by the differing excited-state energies and redox potentials for the differing chromophores. The positive shift of the pendant amine oxidation potential upon complexation of the macrocyclic amines with $\mathrm{Zn}$ (II) is such that the free energy change for PET becomes prohibitive for $\left[\mathrm{ZnL}^{2}\right]^{2+}$ but remains favorable for the $\left[\mathrm{ZnL}^{1}\right]^{2+}$ complex.

The biexponential decay behavior of both $\left[\mathrm{ZnL}^{1}\right]^{2+}$ and $\left[\mathrm{ZnL}^{2}\right]^{2+}$ systems observed by time-resolved fluorescence studies can be readily explained in terms of two differing solution conformers. Despite repeated efforts utilizing several chromatographic techniques, these isomers were not separable, possibly due to kinetic lability of the bound metal ion. It has been previously observed ${ }^{34}$ that crystallized $\mathrm{Zn}$ (II) complexes of the structurally related cyclam macrocycle, with a known configuration of $\mathrm{N}$-donors, rapidly isomerize to give an equilibrium distribution when redissolved, and it is likely that a similar situation applies in this case. As such, the decay behavior of both $\mathrm{Zn}$ (II) complexes is in accord with the ${ }^{1} \mathrm{H}$ NMR $\mathrm{Zn}$ (II) complexation titrations, which demonstrated the appearance of two differing methylene linker resonances. Furthermore, the integrated intensities of these peaks are in close agreement with the relative amplitudes of the major and minor decay components determined by TCSPC as shown in Table 1 . As such, the differing lifetimes may be assigned to emission from differing $\mathrm{N}$-based isomers of the $\mathrm{Zn}$ (II) complexes. On the basis of the results from molecular modeling, the shorter of the two lifetimes $\left(\left[\mathrm{ZnL}^{1}\right]^{2+}=3.34 \mathrm{~ns}\right.$ and $\left.\left[\mathrm{ZnL}^{2}\right]^{2+}=2.21 \mathrm{~ns}\right)$, present as the major component, would correspond to the tetradentate $\alpha \alpha$ trans-III N-based isomer. An inspection of Figure 6 shows that the chromophore in this case has an axial $(\alpha)$ disposition with respect to the coordinated secondary amines. It is therefore proposed that the longer lived component $\left(\left[\mathrm{ZnL}^{1}\right]^{2+}=10.44\right.$ ns and $\left[\mathrm{ZnL}^{2}\right]^{2+}=7.78 \mathrm{~ns}$ ) would likely correspond to an $\mathrm{N}$-based isomer(s) with an equatorial $(\beta)$ disposition of the fluorophore. The relative proportions are also supported by this assignment since, for reasons that are most likely steric, there is a notable increase in the modeled strain energies of complexes with an equatorially disposed fluorophore. This tendency is greatest for the larger anthracene fluorophore, which consequently has a much greater preference to adopt an axial $(\alpha)$ 
configuration. For the smaller naphthalene chromophore, this preference is not as great, and there is a corresponding increase in the relative proportion of the $\mathrm{N}$-based isomer(s) with an equatorially $(\beta)$ oriented chromophore.

The lifetimes of the $\mathrm{Zn}(\mathrm{II})$ complexes are, generally, somewhat shorter than those of the parent chromophores and related systems, ${ }^{43-45}$ with the difference being most apparent for $\left[\mathrm{ZnL}^{1}\right]^{2+}$. In this case, however, the reduced lifetime is related to the presence of a significant PET quenching pathway involving the noncoordinated pendant amines. For $\left[\mathrm{ZnL}^{2}\right]^{2+}$, steady-state measurements have shown that this PET pathway is inoperative; hence, the lifetimes are more closely related to the parent chromophore. For example, the 2.21 ns lifetime assigned to the tetradentate $\alpha \alpha$-trans-III $\mathrm{N}$-based isomer is comparable to that reported ${ }^{46}$ for 9 -methylanthracene in cyclohexane solution at $25^{\circ} \mathrm{C}$ of $3.98 \mathrm{~ns}$. The slight discrepancy observed may be attributed to the known sensitivity of the anthracene lifetime to substitution, or perhaps a solvent effect. ${ }^{25,47}$ Additionally, the presence of a heavy $\mathrm{Zn}$ (II) atom in proximity to the fluorophore could also act to reduce the fluorophore's lifetime by enhancing the rate of intersystem crossing $\left(k_{\text {isc }}\right)$, and this may be cited as another possible reason for the decrease in the decay time observed here. This is consistent with the observed differences in fluorescence lifetime for the axially versus equatorially oriented chromophore. In the former case, the intramolecular distance between fluorophore and coordinated metal ion is smaller, resulting in a greater quenching effect.

\section{Conclusions}

Without exception, the steady-state fluorescence of the ligands in their free base form is efficiently quenched, and this effect has been attributed to a reductive PET quenching mechanism with the macrocyclic amines acting as electron donors. In several cases, the photogenerated products of this PET reaction along with exciplex emission were observed using emission, transient grating, and EPR spectroscopy. Upon complexation with $\mathrm{Zn}(\mathrm{II})$, the $\left[\mathrm{ZnL}^{1}\right]^{2+}$ and $\left[\mathrm{ZnL}^{2}\right]^{2+}$ complexes may form several $\mathrm{N}$-based isomers in solution. However, as demonstrated by ${ }^{1} \mathrm{H}$ NMR, there was a strong propensity for only two isomers to emerge, the major of these assigned to the tetradentate $\alpha \alpha$-transIII form through molecular mechanics calculations, while the other, present to a lesser extent, was ascribed to an N-based isomer with an equatorially disposed pendant chromophore. The ensuing $\left[\mathrm{ZnL}^{1}\right]^{2+}$ and $\left[\mathrm{ZnL}^{2}\right]^{2+}$ complexes displayed remarkably different photophysical behavior, which was attributed to the difference in the redox potentials and excited state energies of the naphthalene and anthracene chromophores, respectively. In the former case, the significantly greater oxidizing potential of the naphthalene excited state resulted in persistent PET activity of the noncoordinated macrocyclic amine donors upon complexation, whereas for $\left[\mathrm{ZnL}^{2}\right]^{2+}$, this quenching pathway was effectively deactivated.

Recently, a series of $\mathrm{N}$-functionalized tetraazamacrocycles appended with an anthraquinone DNA intercalator appeared in the literature and was found to display significantly enhanced binding ability, inducing the unwinding of DNA from its supercoiled to open-circular form. ${ }^{14}$ The structural similarity and photoactivity of the $\left[\mathrm{ZnL}^{1}\right]^{2+}$ and $\left[\mathrm{ZnL}^{2}\right]^{2+}$ complexes in the present case, together with the known intercalating ability of the anthracene chromophore, ${ }^{4}$ may provide interesting avenues for the further exploration of these compounds in terms of developing sequence specific photolytic DNA cleavage reagents.
Acknowledgment. E.G.M. gratefully acknowledges the award of a Graduate School Research Travel Award (GSRTA) from the University of Queensland and the Arlo D. Harris Travel Award from the Department of Chemistry. Assistance by Dr. Tri Le (Chemistry Department, University of Queensland) with EPR experiments is also gratefully acknowledged.

Supporting Information Available: Electronic spectra of free ligands and $\mathrm{Zn}$ (II) complexes, fluorescence decay profile of $\mathrm{L}^{3}$ measured by fluorescence up-conversion, and EPR spectrum of $\mathrm{L}^{1}$ and $\mathrm{L}^{2}$ under $\mathrm{UV}$ irradiation. This material is available free of charge via the Internet at http://pubs.acs.org.

\section{References and Notes}

(1) de Silva, A. P.; Gunaratne, H. Q. N.; Gunnlaugsson, T.; Huxley, A. J. M.; McCoy, C. P.; Rademacher, J. T.; Rice, T. E. Chem. Rev. 1997 97, 1515 .

(2) Bissell, R. A.; Prasanna de Silva, A.; Gunaratne, H. Q. N.; Lynch, P. L. M.; Maguire, G. E. M.; McCoy, C. P.; Sandanayake, K. R. A. S. Top Curr. Chem. 1993, 168, 223.

(3) Herman, P.; Murtaza, Z.; Lakowicz, J. R. Anal. Biochem. 1999 272,87

(4) Kumar, C. V.; Asuncion, E. H. J. Am. Chem. Soc. 1993, 115, 8547

(5) Mei, M.-H.; Yan, J.-J.; Wu, S.-K. W. Ниа. Хие. 2002, 18, 686.

(6) Greiner, G.; Maier, I. J. Chem. Soc., Perkin Trans. 2002, 1005.

(7) Engeser, M.; Fabbrizzi, L.; Licchelli, M.; Sacchi, D. Chem. Commun. 1999, 1191

(8) Sclafani, J. A.; Maranto, M. T.; Sisk, T. M.; Van Arman, S. A Tetrahedron Lett. 1996, 37, 2193.

(9) Mei, M.; Wu, S. W. Ниа. Хие. 2000, 16, 559

(10) Funston, A. M.; Ghiggino, K. P.; Grannas, M. J.; McFadyen, W D.; Tregloan, P. A. J. Chem. Soc., Dalton Trans. 2003, 3704.

(11) De Santis, G.; Fabbrizzi, L.; Licchelli, M.; Mangano, C.; Sacchi, D. Inorg. Chem. 1995, 34, 3581 .

(12) Bernhardt, P. V.; Flanagan, B. M.; Riley, M. J. J. Chem. Soc., Dalton Trans. 1999, 3579.

(13) Bernhardt, P. V.; Moore, E. G.; Riley, M. J. Inorg. Chem. 2001, $40,5799$.

(14) Ellis, L. T.; Perkins, D. F.; Turner, P.; Hambley, T. W. J. Chem Soc., Dalton Trans. 2003, 2728.

(15) Bernhardt, P. V.; Sharpe, P. C. Inorg. Chem. 2000, 39, 4123

(16) Morandeira, A.; Engeli, L.; Vauthey, E. J. Phys. Chem. A 2002 106,4833

(17) Hoegemann, C.; Pauchard, M.; Vauthey, E. Rev. Sci. Instrum. 1996, 67,3449 .

(18) Vauthey, E. J. Phys. Chem. A 2001, 105, 340.

(19) Comba, P.; Hambley, T. W.; Lauer, G.; Okon, N. MOMEC 97, Version 2.1.3; University of Heidelberg: Heidelberg, 1996.

(20) Bernhardt, P. V.; Comba, P. Inorg. Chem. 1992, 31, 2638.

(21) Sayle, R. A.; Bissell, R. A. Rasmol, Version 2.6; 1992.

(22) Sayle, R. A.; Milner-White, E. J. Trends Biochem. Sci. 1995, 20 374.

(23) Friedel, R. A.; Orchan, M. Ultraviolet Spectra of Aromatic Compounds; Wiley: London; Chapman \& Hall: New York, 1951.

(24) Crosby, G. A.; Demas, J. N. J. Phys. Chem. 1971, 75, 991

(25) Nijegorodov, N.; Mabbs, R.; Winkoun, D. P. Spectrochim. Acta A 2003, 59A, 595 .

(26) Van, S.-P.; Hammond, G. S. J. Am. Chem. Soc. 1978, 100, 3895.

(27) Szczepanski, J.; Heldt, J. Z. Naturforsch., A: Phys. Sci. 1985, 40A, 849

(28) Goldschmidt, C. R.; Ottolenghi, M. Chem. Phys. Lett. 1970, 4, 570.

(29) Shida, T. Electronic Absorption Spectra of Radical Ions; Elsevier: Amsterdam, 1988.

(30) Ruoff, R. S.; Kadish, K. M.; Boulas, P.; Chen, E. C. M. J. Phys Chem. 1995, 99, 8843.

(31) Bernhardt, P. V.; Lawrance, G. A.; Maeder, M.; Rossignoli, M.; Hambley, T. W. J. Chem. Soc., Dalton Trans. 1991, 1167.

(32) Bosnich, B.; Poon, C. K.; Tobe, M. L. Inorg. Chem. 1965, 4, 1102.

(33) Alcock, N. W.; Berry, A.; Moore, P. Acta Crystallogr. C 1992, C48, 16 .

(34) Liang, X.; Weishaeupl, M.; Parkinson, J. A.; Parsons, S.; McGregor, P. A.; Sadler, P. J. Chem.-Eur. J. 2003, 9, 4709.

(35) Bernhardt, P. V.; Hayes, E. J. Inorg. Chem. 2002, 41, 2892.

(36) Bernhardt, P. V.; Moore, E. G.; Riley, M. J. Inorg. Chem. 2002 41,3025 .

(37) Bernhardt, P. V.; Creevey, N. L. J. Chem. Soc., Dalton Trans. 2004, 914.

(38) Maiti, A. K. Chem. Phys. Lett. 1987, 134, 450.

(39) Rehm, D.; Weller, A. Isr. J. Chem. 1970, 8, 259. 
(40) Siemiarczuk, A.; Wagner, B. D.; Ware, W. R. J. Phys. Chem. 1990, 94, 1661.

(41) Wlodarczyk, J.; Kierdaszuk, B. Biophys. J. 2003, 85, 589.

(42) Beer, P. D.; Bernhardt, P. V. J. Chem. Soc., Dalton Trans. 2001, 1428.

(43) Berlman, I. B. Handbook of Fluorescence Spectra of Aromatic Molecules; Academic Press: New York, London, 1965.
(44) Nijegorodov, N. I.; Downey, W. S. Spectrochim. Acta A 1995, 51, 2335 .

(45) Nishimura, Y.; Yasuda, A.; Speiser, S.; Yamazaki, I. Chem. Phys. Lett. 2000, 323, 117.

(46) Blatt, E.; Treloar, F. E.; Ghiggino, K. P.; Gilbert, R. G. J. Phys. Chem. 1981, 85, 2810.

(47) Nijegorodov, N.; Mabbs, R. Spectrochim. Acta A 2000, 56, 2157. 